\title{
Socioeconomic inequalities in mortality and importance of perceived control: cohort study
}

\author{
Hans Bosma, Carola Schrijvers, Johan P Mackenbach
}

Perceived control has convincingly been suggested to be a key concept in explaining socioeconomic differences in health. ${ }^{1}$ Some empirical evidence exists of a higher prevalence of low control beliefs (such as powerlessness or fatalism) in lower socioeconomic groups and that this is relevant to socioeconomic inequalities in general health. ${ }^{2}$ However, a systematic examination of the extent to which perceived control contributes to socioeconomic inequalities in mortality is lacking. This is important, as attention has recently shifted towards psychological and psychosocial explanations of socioeconomic inequalities in health.

\section{Participants, methods, and results}

Data were collected in 1991 within the framework of a general population study of the health and living conditions of the population of Eindhoven and its surroundings (the GLOBE study). ${ }^{3}$ We invited a random subsample for interview. The response rate was $80 \%$ and not related to demographic characteristics. Interview data were available for 1220 men and 1242 women aged 25-74 (51 on average). Detailed information was obtained on socioeconomic status (educational, occupational, and income level), health status (self reports of at least one severe chronic condition $(339,14 \%)$, at least one less severe chronic condition $(1062,43 \%)$, and less than good general health $(737,30 \%))$, and perceived control. Perceived control was measured with an 11 item Dutch version of Rotter's locus of control scale (Cronbach's $\alpha=0.84$ ). This asks respondents to indicate agreement with statements using a five point scale-for example, "I often feel a victim of circumstances" $(1=$ strongly disagree, $5=$ strongly agree). ${ }^{4}$ The scores were summed $($ mean $(\mathrm{SD})=31(7.1))$. Municipal population registers provided information on all cause mortality during a six year follow up. There were 122 deaths, and only 30 people were lost to follow up. The analyses were done with Cox proportional hazards model.

The table shows that the socioeconomic indicators were related to mortality in the expected direction. For example, the risk of dying for people with only primary schooling was 2.64 times higher than the risk for the highest educated group. The association was not significant for income level. Perceived low control was more common among low socioeconomic groups and it was also related to mortality. People scoring 1 SD higher on the perceived control scale (indicating decreased control) had a 1.45 times higher mortality risk $(95 \%$ confidence interval 1.19 to 1.75$)$. Adjustment for perceived control substantially decreased the mortality ratios for the lower socioeconomic groups. The mortality ratio for people with only primary schooling decreased to 1.76. This implies that more than half $((2.64-1.76) /(2.64-1)=0.54)$ of the raised risk in this group is accounted for by perceived low control. The average percentage of raised mortality risk in the lowest socioeconomic groups that was accounted for by perceived low control was $51 \%$ (range: $37-65 \%$ ).

\section{Comment}

Our findings indicate that low socioeconomic status is related to mortality partly because people with a low socioeconomic status more often perceive low control. This supports hypotheses on the importance of perceived control for socioeconomic inequalities in health. ${ }^{1}$ Perceptions of low control partly originate in adverse socioeconomic conditions during childhood.
Erasmus University Rotterdam, Medical School, Departmen of Public Health, PO Box 1738, 3000 DR Rotterdam, Netherlands

Hans Bosma senior researcher Carola Schrijvers senior researcher Johan P

Mackenbach director, GLOBE study

Correspondence to: H Bosma h.bosma@np. unimaas.nl.

BMJ 1999;319:1469-70

\begin{tabular}{|c|c|c|c|c|c|}
\hline & $\begin{array}{l}\text { No of } \\
\text { people* }\end{array}$ & $\begin{array}{l}\text { No (\%) who } \\
\text { died during } \\
\text { follow up }\end{array}$ & $\begin{array}{c}\text { Adjusted } \\
\text { mortality ratio }\end{array}$ & $\begin{array}{c}\text { Mortality ratio } \\
\text { additionally adjusted for } \\
\text { perceived control }\end{array}$ & $\begin{array}{l}\% \text { reduction in } \\
\text { mortality ratio } \\
\text { between } 2 \text { models }\end{array}$ \\
\hline \multicolumn{6}{|l|}{ Educational level: } \\
\hline University/higher vocational & 469 & $9(2)$ & 1.00 & 1.00 & \\
\hline Intermediately high & 489 & $19(4)$ & 1.48 (0.65 to 3.39$)$ & 1.22 (0.53 to 2.82$)$ & 54 \\
\hline Intermediately low & 909 & $36(4)$ & 1.67 (0.80 to 3.52$)$ & $1.29(0.60$ to 2.78$)$ & 57 \\
\hline Primary school only & 541 & $58(11)$ & 2.64 (1.26 to 5.51$)$ & $1.76(0.80$ to 3.85$)$ & 54 \\
\hline \multicolumn{6}{|l|}{ Occupational level: } \\
\hline Higher grade professionals & 259 & $7(3)$ & 1.00 & 1.00 & \\
\hline Lower grade professionals & 724 & $31(4)$ & 1.86 (0.81 to 4.27$)$ & 1.51 (0.64 to 3.53 ) & 41 \\
\hline Self employed & 86 & $5(6)$ & 1.56 (0.49 to 4.99$)$ & 1.31 (0.41 to 4.21$)$ & 45 \\
\hline Manual workers & 606 & $49(8)$ & 2.43 (1.08 to 5.44$)$ & 1.72 (0.74 to 3.99$)$ & 50 \\
\hline \multicolumn{6}{|l|}{ Income level: } \\
\hline Highest quarter & 552 & $15(3)$ & 1.00 & 1.00 & \\
\hline Second highest quarter & 522 & $19(4)$ & 1.46 (0.73 to 2.93$)$ & 1.29 (0.64 to 2.59) & 37 \\
\hline Second lowest quarter & 542 & $41(8)$ & 1.76 (0.94 to 3.28$)$ & 1.33 (0.70 to 2.56$)$ & 57 \\
\hline Lowest quarter & 547 & $35(6)$ & $1.62(0.85$ to 3.11$)$ & $1.22(0.62$ to 2.40$)$ & 65 \\
\hline
\end{tabular}

*Numbers differed between the socioeconomic indicators because the indicators had differing numbers of people with missing data. Housewives were excluded from the analyses for occupational level. Excluded people did not differ in their risk of mortality from those included.

†Adjusted for age, sex, severe chronic conditions, less severe chronic conditions, and general health in 1991. 
We found that low socioeconomic status in adulthood was related to adverse changes in control beliefs during the six year follow up (results not shown), suggesting that adult socioeconomic conditions further contribute to beliefs of low control. More information is needed on the specific socioeconomic correlates that induce beliefs of low control as these may be easier to modify than the beliefs themselves. Low job control may be one of these conditions. ${ }^{5}$ Other studies with larger numbers are needed to examine the behavioural or psychophysiological pathways through which perceived control affects mortality. Our findings emphasise that only by examining psychological mechanisms more thoroughly can we determine the complex pathways through which social structure affects individual disease and mortality.

The study was conducted in close collaboration with the Public Health Services of the Dutch city of Eindhoven and the region of South-East Brabant. We thank Michel Provoost and Ilse Oonk for carefully constructing the database and Mariel Droomers for providing comments on previous drafts of the paper.
Contributors: $\mathrm{HB}$ was the main author, formulated the hypothesis, carried out the analyses, interpreted data, and was partly responsible for data collection. CS helped with writing and interpreting data and was partly responsible for data collection. JPM was principal investigator, helped with writing and interpreting data, was responsible for data collection, and is guarantor for the study.

Funding: Dutch Ministry of Public Health, Welfare, and Sports and the Dutch Prevention Fund.

Competing interests: None declared.

1 Syme SL. Control and health: a personal perspective. In: Steptoe A, Appels A, eds. Stress, personal control and health. London: Wiley, 1989:3-18.

2 Bosma $\mathrm{H}$, Mheen $\mathrm{HD}$ van de, Mackenbach JP. Social class in childhood and general adult health in adulthood: a questionnaire study of contribution of psychological attributes. BMJ 1999;318:18-22

3 Mackenbach JP, Mheen HD van de, Stronks K. A prospective cohort study investigating the explanation of socio-economic inequalities in health in the Netherlands. Soc Sci Med 1994;38:299-308.

4 Rotter J. Generalized expectancies for internal versus external control of reinforcement. Psychol Monogr 1966;80:1-28.

5 Marmot MG, Bosma H, Hemingway H, Brunner E, Stansfeld S. Contribution of job control and other risk factors to social variations in coronary heart disease incidence. Lancet 1997:349:235-9.

(Accepted 7 September 1999)
Health Care

Evaluation Unit,

Department of

Public Health

Sciences,

St George's

Hospital Medical

School, London

SW17 0RE

Joanne Lord

lecturer in health

economics

Peter Littlejohns professor

Rachel Churchill

senior research fellow

continued over

BMJ 1999;319:1470-1

website

extra

A table with

baseline data is on

the BMJ's website

www.bmj.com

\title{
Cost effectiveness analysis of inhaled anticholinergics for acute childhood and adolescent asthma
}

\author{
Joanne Lord, Francine M Ducharme, Ronald J Stamp, Peter Littlejohns, Rachel Churchill
}

A recent systematic review by the Cochrane Airways Group showed that adding multiple doses of anticholinergics to $\beta_{2}$ agonists is safe and effective in improving lung function and avoiding hospital admission for school aged children and adolescents attending casualty departments with severe acute asthma. $^{1}$ The estimated reduction in the risk of admission was $9.4 \%$ ( $0.4 \%$ to $18.4 \%)$. This intervention presumably improves bronchodilatation until systemic corticosteroids take effect. Evidence of cost effectiveness, however, is lacking. To clarify whether scarce health resources should be spent on this intervention we conducted an economic evaluation.

\section{Methods and results}

We used various assumptions to estimate the financial implications of treatment (see table on the BMJ's

Results of baseline analysis, with uncertainty ranges estimated by probabilistic sensitivity analysis

\begin{tabular}{lcc} 
& \multicolumn{2}{c}{ Per severe case treated } \\
\cline { 2 - 3 } & Best estimate & Uncertainty range \\
\hline Admissions avoided $\dagger$ & 0.09 & $0-0.18$ \\
\hline Cost of treatment & $£ 0.75$ & $£ 0.28-£ 1.40$ \\
\hline Savings due to avoided admissions§ & $£ 81$ & $£ 0-£ 158$ \\
\hline Cost of treatment per admission avoided & $£ 8$ & $£ 1-£ 47$ \\
\hline Net monetary saving to the health service** & $£ 80$ & $£ 0-£ 157$ \\
\hline
\end{tabular}

*Interval containing $95 \%$ of 5000 simulation replications. †Risk difference estimated by meta-analysis. ${ }^{1}$ ¥Cost of ipratropium bromide 25p per $0.25 \mathrm{mg}$ (from British National Formulary March 1999), and total dose per patient $0.625 \mathrm{mg}$ (median for multiple dose protocols included in the meta-analysis ${ }^{1}$ ). Authors assumed that one mild to moderate case is treated for every five severe cases treated.

$\S$ Mean cost of non-elective inpatient admissions £860 (NHS Executive's reference costs 1998 (HRG D21 and D22)). ๆCost of treatment divided by the number of admissions avoided.

${ }^{* *}$ Savings due to avoided admissions minus the cost of treatment. website). The costs of drug administration were not included, as anticholinergics are always given with $\beta_{2}$ agonists and involve little additional manipulation. The cost of nebulisers, other drugs, and the casualty attendance were also excluded. No consideration was given to possible changes in length of stay in casualty. The effect of changing the various assumptions was tested by simple, one way, sensitivity analysis, and by multivariate probabilistic sensitivity analysis. ${ }^{2}$ The latter is a simulation approach that enables estimation of uncertainty ranges containing $95 \%$ of replicated results. ${ }^{3}$

We estimated that treatment would cost about $£ 8$ (uncertainty range $£ 1$ to $£ 47$ ) per admission avoided (table). This implies a net saving of $£ 80$ ( $£ 0$ to $£ 157$ ) per severe case treated. Varying the risk reduction within $95 \%$ confidence limits varied the mean net saving from $£ 3$ to $£ 157$ per severe case treated. More precision is expected when the Cochrane review is updated. Varying the cost of hospital admissions within the interquartile range for English providers (£620 to $£ 907$ ) varied the mean savings from $£ 58$ to $£ 85$ per severe case treated. Changes to the dose and unit cost of ipratropium had very little effect on the results.

Further assumptions were used to extrapolate the findings to a national level. About 7200 children aged 5-15 years are admitted from casualty with a diagnosis of asthma each year (hospital episode statistics 1988 to 1996). About $40 \%$ of children in this age group attending casualty with asthma are admitted. ${ }^{4}$ We assumed that $50 \%$ of people with asthma attending casualty have severe asthma. The rate of uptake of the review recommendations was assumed to be $5 \%$ a 